\title{
Radiographic aspects of major salivary glands in sialography
}

\begin{abstract}
- Lucas Morita Department of Oral Radiology, School of Dentistry, University of São Paulo, São Paulo, SP, Brazil • Vagner Braga Da Silva Department of Oral Radiology, School of Dentistry, University of São Paulo, São Paulo, SP, Brazil • Letícia Mayumi Takeda Department of Oral Radiology, School of Dentistry, University of São Paulo, São Paulo, SP, Brazil • Isabela Goulart Gil Choi Department of Oral Radiology, School of Dentistry, University of São Paulo, São Paulo, SP, Brazil • Jun Ho Kim Department of Oral Radiology, School of Dentistry, University of São Paulo, São Paulo, SP, Brazil • Miki Hisatomi Department of Oral and Maxillofacial Radiology, Okayama University Dental School, Okayama, Japan • Emiko Saito Arita Department of Oral Radiology, School of Dentistry, University of São Paulo, São Paulo, SP, Brazil
\end{abstract}

ABSTRACT | Objective: The aim of this study was to evaluate the radiographic aspects of the major salivary glands in sialography and their grade of inflammation with patients' individual characteristics. Methods: A total of 30 radiographic images of both parotid and submandibular glands from 25 patients, who underwent sialography examinations, were retrospectively analyzed. Chi-squared test was performed to correlate the grade of inflammation of each area of the salivary glands with the categorical variables: sex, type and side of the affected gland. Pearson correlation was performed to correlate the grade of inflammation between the main duct and the intraglandular duct and the parenchyma. Results: There was no statistically significant relationship between the grade of inflammation of any of the parts of the salivary glands and the categorical variables in the Chi-squared test ( $>>0.05)$. The grade of inflammation in the main duct had a weak correlation with the degree of inflammation in the intraglandular duct $(\mathrm{p}<0.05)$. Conclusions: Salivary glands affected by obstruction or inflammation are not significantly related to the sex of patients, not to the type or side of the affected gland. The , but sialography examination demonstrated the delicate anatomy of the ductal system and allowed an accurate visualization of sialoliths and strictures that are two of the most common causes of obstruction, showing its important role in the assessment of salivary gland status.

DESCRIPTORS | Sialography; Salivary Glands; Salivary Gland Calculi; Sialadenitis; Diagnosis, Oral.

RESUMO | Aspectos radiográficos das glândulas salivares maiores na sialografia • Objetivo: O objetivo deste estudo foi avaliar os aspectos radiográficos das glândulas salivares maiores na sialografia e seu grau de inflamação com as características individuais dos pacientes. Métodos: Trinta imagens radiográficas de ambas as glândulas parótidas e submandibulares de 25 pacientes submetidos a exames de sialografia foram analisadas retrospectivamente. O teste qui-quadrado foi realizado para correlacionar o grau de inflamação de cada área das glândulas salivares com as variáveis categóricas: sexo, tipo e lado da glândula afetada. A correlação de Pearson foi realizada para correlacionar o grau de inflamação entre o ducto principal e o ducto intraglandular e o parênquima. Resultados: Não houve relação estatisticamente significante entre o grau de inflamação de nenhuma das partes das glândulas salivares e as variáveis categóricas no teste qui-quadrado $(\mathrm{p}>0,05)$. O grau de inflamação no ducto principal teve uma fraca correlação com o grau de inflamação no ducto intraglandular $(\mathrm{p}<0,05)$. Conclusões: As glândulas salivares afetadas por obstrução ou inflamação não estão significativamente relacionadas ao sexo dos pacientes e nem ao tipo ou lado da glândula afetada. $O$ exame de sialografia demonstrou a delicada anatomia do sistema ductal e permitiu uma visualização precisa dos sialólitos e estenoses, que são duas das causas mais comuns de obstrução, mostrando seu importante papel na avaliação do estado das glândulas salivares.

DESCRITORES | Sialografia; Glândulas Salivares; Cálculos das Glândulas Salivares; Sialadenite; Diagnóstico Bucal.

CORRESPONDING AUTHOR | • Isabela Goulart Gil Choi Department of Oral Radiology, School of Dentistry University of São Paulo • Av. Prof. Lineu Prestes, 2227 São Paulo, SP, Brazil • 05508-000 E-mail: isabelaggilchoi@gmail.com

- Received Sep 15, 2018 • Accepted Jan 15, 2019

- Dol http://dx.doi.org/10.11606/issn.2357-8041.clrd.2019.150319 


\section{INTRODUCTION}

Salivary glands are exocrine glands that are known to have two subdivisions: the three paired major glands (parotid, submandibular, sublingual) and hundreds of minor salivary glands. ${ }^{1}$

Among the major salivary glands, the parotid gland can be classified as a serous gland and is located in the retromandibular fossa; the submandibular gland is considered seromucous (mixed gland) and it lies in the posterior part of the submandibular triangle; finally, the sublingual gland is mucous and is between the muscles of the oral cavity floor: the geniohyoid muscle, an intrinsic muscle of the tongue, the hyoglossus muscle (medially) and the mylohyoid muscle. ${ }^{2}$

Different inflammatory and obstructive disorders can affect the major salivary glands more frequently than the small and minor ones. These disorders may be caused by different conditions: sialolithiasis, where a calcified mass or sialolith forms within a salivary gland, autoimmune diseases such as Sjogren's syndrome (SS), and benign or malignant neoplastic lesions. ${ }^{3}$

Diagnostic imaging has an important role in the diagnostic approach of salivary gland disorders. Ultrasonography, computed tomography (CT), magnetic resonance imaging (MRI) examinations and sialography are used to assist in the diagnosis of different disorders. The best imaging method will be the one that best fits the clinical situation of each patient. ${ }^{1,4}$

The sialography technique is the radiographic examination of the salivary glands in which a small amount of contrast medium is injected into the salivary duct, followed by routine X-ray projections. Technological advances have brought back sialography as an important diagnostic x-ray tool, after being neglected for many years. Especially with the introduction of sialoendoscopy, sialography has regained an important role to assess salivary gland status. ${ }^{5}$
Thus, the aim of this study was to evaluate the radiographic aspects of the major salivary glands in sialography and their degree of inflammation with the individual characteristics of patients.

\section{MATERIALS AND METHODS}

Radiographic images of parotid and submandibular glands diagnosed with inflammatory diseases were included in the sample to be analyzed. Approval was obtained from the University's research ethics committee (protocol number: 2523031) to use the radiographic images from the school database and to conduct this research.

Of 30 images, five were diagnosed with tumors and had to be excluded from the sample. Therefore, a total of 25 radiographic images of both parotid and submandibular glands from 25 patients, who underwent sialography examinations at the Dentistry School of the University of São Paulo, were retrospectively analyzed.

These 25 patients included 16 females and 9 males with an average age of 42 years, with ages ranging from 25 to 63 years. They had no medication histories that influenced the secretion of saliva.

Due to the absence of a complete anamnesis including all signs and symptoms of all patients at the time of the examination, statistical analysis was performed to compare and correlate the degree of inflammation of each area of the salivary gland (main duct, intraglandular duct and parenchyma) with the following categorical variables: gender, side (right/left gland) and type of gland (submandibular/ parotid).

These three variables were chosen for statistical analysis, because they were the unanimous information in all the clinical records from the patients. Other specific points like the presence of swelling, pain and characteristics of salivary secretion were not available for all the cases. 


\section{Sialography}

Conventional sialography had been performed at the time of the examinations for all the analyzed images: the sialography device included a watersoluble, nonionic contrast agent - Ultavist 370 -, sialography cannula or a $23-\mathrm{G}$ butterfly needle, a polyethylene connecting tube and a 5 -ml syringe. The orifice was identified, and the contrast agent was slowly injected using manual pressure, after the cannula or butterfly needle was placed into the orifice. Panoramic radiograph was obtained after injecting from 1.5 to 4.0 $\mathrm{ml}$ of contrast agent. 10 minutes after removing the cannula, a panoramic or lateral radiograph was taken again to examine the retention of the contrast agent.

All panoramic and lateral radiographic images were taken using the same device (Instrumentarium Orthopantomograph OP100). Imaging parameters were adjusted for optimum image density and contrast for each patient.

\section{Classification of inflammation}

The degree of inflammation in sialographic images was evaluated in 3 areas (main duct, intraglandular duct and parenchyma) using 4 rating scores - according to the classification by Choi et al. ${ }^{6}$ - that had to be agreed upon by 4 oral and maxillofacial radiologists. The main duct was defined as the part from the orifice to the bifurcation point.

Inflammation of the main duct was classified into 4 degrees. The ducts in the normal group included those with uniform thickness and a smooth surface continuity but without dilatation or stricture. Ducts of the slight inflammation group (Degree 2) included ducts with slight dilatations and/or irregular surface margins. Ducts in the moderate inflammation group
(Degree 3) showed 2 or more findings including generalized dilatation, stricture, and an irregular course of the main duct. The ducts in the severe inflammation group (Degree 4) had severe dilatation and strictures and were sausage-string-like in appearance (Figure 1).

The intraglandular duct was defined as the proximal part from the bifurcation point of the main duct to the posterior margin of the parotid or submandibular gland. Inflammation of the intraglandular duct was classified into 4 degrees. Ducts in the normal group (Degree 1) were thinner than the main duct and showed a uniform thickness and a smooth surface continuity. Ducts in the slight inflammation group (Degree 2) had a small dilatation in fewer than one third of all intraglandular ducts. Ducts of the moderate inflammation group (Degree 3) had dilatation in one to two thirds of all the intraglandular ducts. The ducts in the severe inflammation group (Degree 4) showed dilatation in more than two thirds of all intraglandular ducts or had severe dilatation in several ducts (Figure 1). Inflammation of the parenchymal area was classified into 4 degrees. The normal group (Degree 1) showed no acinar dilatation. In the slight inflammation group (Degree 2), the acinar dilatations were scattered throughout less than one third of the entire intraglandular area. Acinar dilatations were divided between one and two thirds of the intraglandular area with or without a few severe dilatations in the moderate inflammation group (Degree 3). In the severe inflammation group, acinar dilatations were scattered in more than two thirds of the intraglandular area with or without severe acinar destruction (Figure 2). 

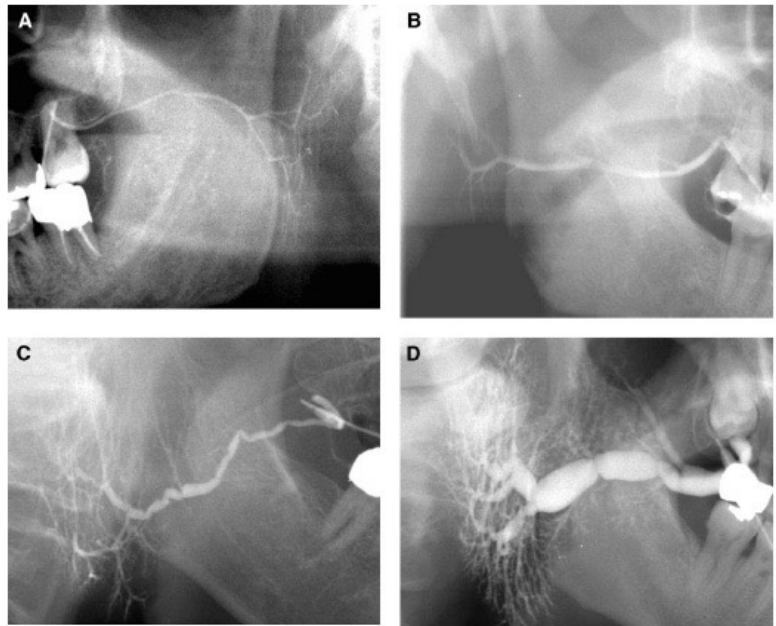

Figure 1 | Degrees of inflammation in the main and intraglandular ducts, according to the classification by Choi et al. ${ }^{6}$. (A) Degree 1 (normal) of the main and intraglandular ducts; (B) Degree 2 (slight inflammation) of the main and intraglandular ducts; (C) Degree 3 (moderate inflammation) of the main and intraglandular ducts; and (D) Degree 4 (severe inflammation) of the main and intraglandular ducts - figure obtained and edited from the study by Choi et al. ${ }^{6} \mathrm{Ar}$ rows are pointing to the different degrees of inflammation.

\section{Statistical Analysis}

Data were analyzed with a statistical software package (SPSS Version 10.0; SPSS Inc., Chicago, IL). The chi-squared test was performed to correlate the degree of inflammation (Degree 1, 2, 3 or 4) of each area of the salivary glands (main duct, intraglandular duct, and parenchyma) and the gender, side of the affected gland (patient's right or left side) and type of major salivary gland (submandibular or parotid gland). Pearson correlation was performed to correlate the degree of inflammation between the main duct, the intraglandular duct and the parenchyma.

\section{RESULTS}

Figure 3 shows two cases of sialolithiases obtained from the analyzed sample - this was one
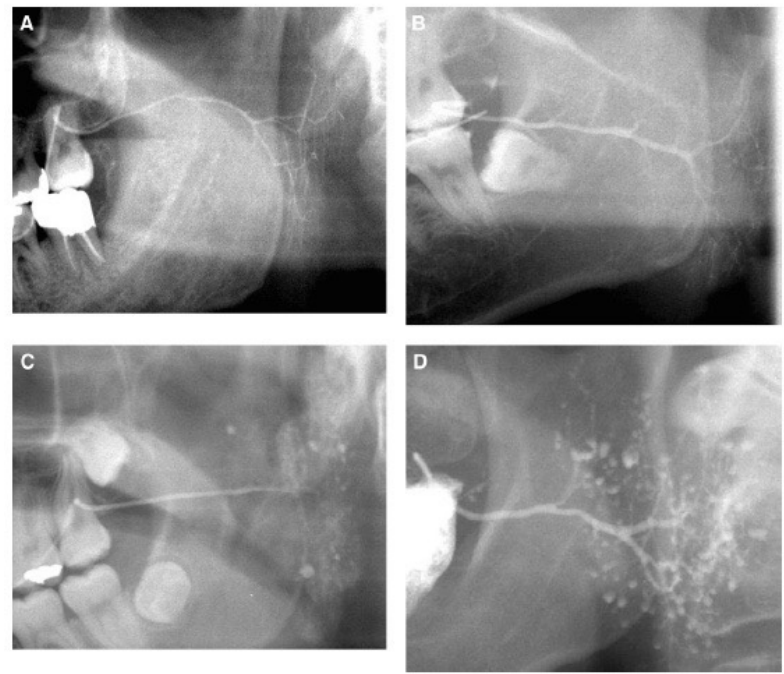

Figure 2 || Degrees of inflammation in the parenchyma. (A) Degree 1 (normal) of sialadenitis; (B) Degree 2 (slight inflammation) of sialadenitis; (C) Degree 3 (moderate inflammation) of sialadenitis; and (D) Degree 4 (severe inflammation) of sialadenitis figure obtained and edited from the study by Choi et al. ${ }^{6}$ Arrows are pointing to the different grades of inflammation in the parenchyma region.

of the most common causes of obstruction and inflammation.

There was no statistically significant relation between the grade of inflammation of any of the parts of the salivary glands and the variables: gender, side and type of the gland in the Chi-squared test (p>0.05), as shown in Tables 1, 2 and 3 .

Table 4 shows the Pearson correlation analysis between the degree of inflammation in the main and intraglandular duct. The degree of inflammation in the main duct had a weak correlation with the one in the intraglandular duct $(\mathrm{p}<0.05)$. There was no significant correlation ( $p>0.05$ ) between the degree of inflammation in the parenchyma and the one in the main and intraglandular ducts. 
Table 1 | Chi-squared test for the relation between the degree of inflammation of the parts of the salivary glands and gender.

\begin{tabular}{l|c|c|c} 
& Female $(\mathrm{n})$ & Male $(\mathrm{n})$ & P-value \\
\hline Main duct & & & \\
\hline Normal & 8 & 2 & \\
\hline Slight & 2 & 4 & 0.244 \\
\hline Moderate & 2 & 0 & \\
\hline Severe & 4 & 1 & \\
\hline Intraglandular duct & & & \\
\hline Normal & 8 & 4 & \\
\hline Slight & 3 & 3 & 0.857 \\
\hline Moderate & 2 & & \\
\hline Severe & & & \\
\hline Parenchyma duct & & & \\
\hline Normal & 13 & 7 & \\
\hline Slight & 1 & 0 & 0.822 \\
\hline Moderate & 1 & 1 & \\
\hline Severe & 1 & 1 & \\
\hline
\end{tabular}

No statistically significant correlation, with $p$-value of 0.05 by the Chi-squared test.

Table 2 | Chi-squared test for the relation between the degree of inflammation of the different parts of the salivary glands and side.

\begin{tabular}{|c|c|c|c|}
\hline & Right side (n) & Left side $(n)$ & P-value \\
\hline \multicolumn{4}{|l|}{ Main duct } \\
\hline Normal & 4 & 8 & \\
\hline Slight & 3 & 3 & 0.755 \\
\hline Moderate & 1 & 1 & \\
\hline Severe & 3 & 2 & \\
\hline \multicolumn{4}{|c|}{ Intraglandular duct } \\
\hline Normal & 8 & 4 & \\
\hline Slight & 3 & 3 & 0.151 \\
\hline Moderate & 0 & 3 & \\
\hline Severe & 1 & 3 & \\
\hline \multicolumn{4}{|c|}{ Parenchyma duct } \\
\hline Normal & 10 & 10 & \\
\hline Slight & 0 & 1 & 0.810 \\
\hline Moderate & 1 & 1 & \\
\hline Severe & 1 & 1 & \\
\hline
\end{tabular}

Table 3 | Chi-squared test for the relation between the degree of inflammation of the different parts of the salivary glands and type of gland.

\begin{tabular}{l|c|c|c} 
& \multicolumn{1}{|c|}{ Submandibular (n) } & Parotid (n) & P-value \\
\hline Main duct & & & \\
\hline Normal & 4 & 8 & \\
\hline Slight & 3 & 3 & 0.735 \\
\hline Moderate & 1 & 1 & \\
\hline Severe & 1 & 4 & \\
\hline Intraglandular duct & & & \\
\hline Normal & 4 & 8 & \\
\hline Slight & 2 & 4 & 0.684 \\
\hline Moderate & 2 & 1 & \\
\hline Severe & 1 & 3 & \\
\hline Parenchyma duct & & & \\
\hline Normal & 8 & 12 & \\
\hline Slight & 0 & 1 & 0.400 \\
\hline Moderate & 0 & 2 & \\
\hline Severe & 0 & 2 & \\
\hline
\end{tabular}

Table 4 | Pearson correlation analysis between the degree of inflammation in the main duct with the intraglandular duct. *Statistically significant at level 0.05 by the Fisher's exact test.

\begin{tabular}{l|c}
\multicolumn{2}{|c}{ Pearson correlation } \\
\hline$R$ & 0.4384 \\
\hline $95 \%$ confidence interval & 0.05238 to 0.7105 \\
\hline$R$ squared & 0.1922 \\
\hline$P$ value & 0.0284 \\
$P$ (two-tailed) & $*$ \\
\hline P value summary & Yes \\
\hline Significant? (alpha=0.05) & 25 \\
\hline Number of $X Y$ pairs &
\end{tabular}
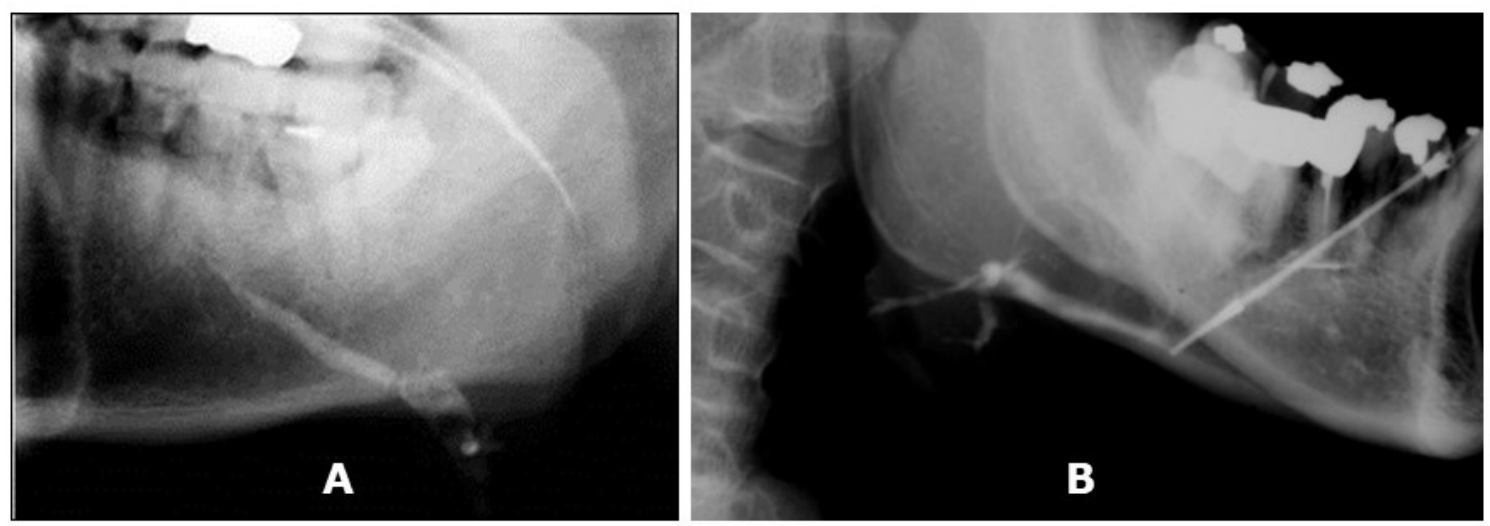

Figure 3 | Two cases of sialolithiase. (A) Plain film radiograph demonstrating a large calcified sialolith - lateral view of left submandibular gland; (B) Plain film radiograph demonstrating a calcified sialolith - lateral view of right submandibular gland. The arrows are pointing to the sialoliths in both images. 


\section{DISCUSSION}

The objective of this study was to evaluate the relation between sialographic images and clinical characteristics of inflammatory parotid and submandibular gland diseases. However, as the images came from a database, the patients' clinical information and history of anamnesis were incomplete, which limited the variables to be evaluated in this study. Thus, statistical analysis was performed to correlate the degree of inflammation of each area of the salivary gland with gender, side and type of the affected gland. The degrees of inflammation and the studied variables were expected to have a significant relation. However, no statistically significant relation was found between the degrees of inflammation and the categorical variables. This result might be due to the small sample of our study: as this imaging method has been less requested by dental surgeons due to the existence of other imaging modalities, only 30 images were obtained and, of these, only 25 images were included in the analyzed sample.

In the study by Choi et al. ${ }^{6}$, in addition to evaluating the degree of inflammation on sialographic images in 3 areas (main duct, intraglandular duct, and parenchyma) by rating 4 degrees, respectively, under the consensus of 3 radiologists, they evaluated the degree of salivation of the patients as well. However, they only assessed parotid gland diseases, whereas, in this study, images of submandibular glands were also included. ${ }^{6}$

Five of the 25 patients had reported having dry eyes, which suggests a diagnosis of SS when combined with inflamed salivary glands. Despite the availability of other advanced imaging techniques, the sialography procedure, which is the oldest technique of all, has recovered its importance and is, indeed, the imaging procedure of choice for evaluating the ductal system to diagnose SS.7

One of the studies that evaluated the accuracy of sialography to diagnose SS showed a high sensibility and specificity in patients with affected parotid glands. ${ }^{7}$ Other studies that have used CT or MRI techniques to diagnose this disease, so that conflicting results have been reported in literature. ${ }^{8,9}$

Other imaging modalities to evaluate sialadenitis affecting major salivary glands are ultrasound, CT and MRI. ${ }^{10}$ The ultrasound (US) technique can offer many advantages because it is widely available and non-invasive. However, US does not show calculi in an accurate way and does not show ductal damage caused by obstruction and inflammation. ${ }^{4}$

The MRI, on the other hand, can show changes in the ductal system and allows a great discrimination between the parenchyma and ductal structures. However, calcified sialoliths may be overestimated because of the signal void associated with calcified structures. ${ }^{3,4}$ Some studies have indicated MR sialography as accurate as x-ray sialography to help diagnosing obstructions, stricture and stenosis. ${ }^{11,12}$

However, MRI exams have the following disadvantages: susceptibility to motion; acquisition time required for a single sequence; cost of the exam and the fact that ductal obstruction due to calcified sialoliths, fibrin or mucous plugs cannot be differentiated due to their similar magnetic susceptibility.,11

The ability of sialography contrast to evaluate the parenchyma and ductal system and the availability of CT techniques led to the combination and development of CT sialography. Similar to an x-ray sialography, a sialography catheter is inserted into the orifice with a contrast agent, then multiplanar images are obtained. ${ }^{11,13}$

In a study by Jadu \& Lam, ${ }^{14}$ they compared the diagnostic capabilities of two-dimensional sialography with a new three-dimensional technique using cone beam CT (CBCT). The authors found that CBCT sialography allowed to better visualize the parenchyma and to identify sialoliths than plain radiographs, and the choice of using lower peak tube potential (80kVp) and milliampere (10mA) settings may lower the radiation dose of the patient. ${ }^{14}$ 
CBCT sialography is a new type of investigation, and there are few case reports in literature, ${ }^{15}$ but this technique helps to confirm the diagnostic value of sialography.,16 However, it is not an exam routinely performed due to its high dose of radiation. Conventional sialography has the advantage, therefore, of using a lower dose of radiation, among many others over the aforementioned imaging modalities: better detection of calcified sialoliths; better visualization of stricture and stenosis; availability; low cost; and quick procedure..$^{14,17,18}$ This confirms the importance of conventional sialography examination in regaining its importance in the assessment of the salivary gland status.

\section{CONCLUSION}

Salivary glands affected by obstruction or inflammation are not significantly related to the gender of the patients, the type or side of the affected glands. Sialography demonstrated the delicate anatomy of the ductal system and allowed to accurately visualize sialoliths and strictures, which are two of the most common causes of obstruction, showing its important role in the assessment of salivary gland status.

\section{REFERENCES}

1. Yousem DM, Kraut MA, Chalian AA. Major salivary gland imaging. Radiology. 2000;216(1):19-29. doi: 10.1148/radiology.216.1.roojl4519

2. Bialek EJ, Jakubowski W, Zajkowski P, Szopinski KT, Osmolski A. US of the major salivary glands: anatomy and spatial relationships, pathologic conditions, and pitfalls. Radiographics. 2006;26(3):745-763. doi: 10.1148/rg.263055024

3. Ugga L, Ravanelli M, Pallottino AA, Farina D, Maroldi R. Diagnostic work-up in obstructive and inflammatory salivary gland disorders. Acta otorhinolaryngologica Italica. 2017;37(2):83-93. doi: 10.14639/0392-10oX-1597

4. Burke CJ, Thomas RH, Howlett D. Imaging the major salivary glands. British Journal of Oral \& Maxillofacial Surgery. 2011;49:261-269. doi: 10.1016/j.bjoms.2010.03.002
5. Hasson O. Modern sialography for screening of salivary gland obstruction. American Journal of Oral and Maxillofacial Surgery. 2010;68(9):276-280. doi: 10.1016/j. joms.2009.09.044

6. Choi JW, Lee SS, Huh KH, Yi WJ, Hoe MS, Choi SC. The relationship between sialographic images and clinical symptoms of inflammatory parotid gland diseases. Oral Surgery, Oral Medicine, Oral Pathology, Oral Radiology. 2009;107(3):e4956. doi: 10.1016/j.tripleo.2008.11.014

7. Kalk WWI, Vissink A, Spijkervet FKL, Bootsma H, Kallenberg CGM, Roodenburg JLN. Parotid sialography for diagnosing Sjögren syndrome. Oral Surgery, Oral Medicine, Oral Pathology, Oral Radiology. 2002;94(1):131-137. doi: 10.1067/ moe.2002.126017

8. Izumi M, Eguchi K, Ohki M, Uetani M, Hayashi K, Kita M, et al. MR imaging of the parotid gland in Sjogren's syndrome: a proposal for new diagnostic criteria. AJR American Journal of Roentgenology. 1996;166(6):1483-1487. doi: 10.2214/ ajr.166.6.8633469

9. de Clerck LS, Corthouts R, Francx L, et al. Ultrasonography and computer tomography of the salivary glands in the evaluation of Sjogren's syndrome. Comparison with parotid sialography. J Rheumatol. 1988;15:1777-1781.

10. Ngu RK, Brown JE, Whaites EJ, Drage NA, Ng SY, Makdissi J. Salivary duct strictures: nature and incidence in benign salivary obstruction. Dentomaxillofacial Radiology. 2007;36(2):63-67. doi: 10.1259/dmfr/24118767

11. Mosier KM. Diagnostic radiographic imaging for salivary endoscopy. Otolaryngologic Clinics. 2009;42(6):949-972. doi: 10.1016/j.otc.2009.08.010

12. Becker M, Marchal F, Becker CD, Dulguerov P, Georgakopoulos G, Lehmann W, et al. Sialolithiasis and salivary ductal stenosis: diagnostic accuracy of MR sialography with a three-dimensional extended-phase conjugate-symmetry rapid spin-echo sequence. Radiology. 2000;217(2):347-358. doi: 10.1148/radiology.217.2.roooc02347

13. McGahan JP, Walter JP, Bernstein L. Evaluation of the parotid gland: comparison of sialography, non-contrast computed tomography, and CT sialography. Radiology. 1984;152(2):453458. doi: 10.1148/radiology.152.2.6739814

14. Jadu FM, Lam EW. A comparative study of the diagnostic capabilities of 2D plain radiograph and $3 \mathrm{D}$ cone beam CT sialography. Dento Maxillo Facial Radiology. 2013;42(1):20110319. doi: 10.1259/dmfr.20110319 
15. Drage NA, Brown JE. Cone beam computed sialography of sialoliths. Dento Maxillo Facial Radiology. 2009;38(5):301305. doi: 10.1259/dmfr/90784441

16. Kalk WW, Vissink A, Spijkervet FK, Moller JM, Roodenburg JL. Morbidity from parotid sialography. Oral Surgery, Oral Medicine, Oral Pathology, Oral Radiology. 2001;92(5):572575. doi: 10.1067/moe.2001.117300
17. van den Akker HP. Diagnostic imaging in salivary gland disease. Oral Surgery, Oral Medicine, Oral Pathology. 1988;66(5):625-637. doi: 10.1016/0030-4220(88)90387-8

18. Zou Z-j, Wang S-l, Zhu J-r, Wu Q-g, Yu S-F. Chronic obstructive parotitis. Oral Surgery, Oral Medicine, Oral Pathology. 1992;73(4):434-440. doi: 10.1016/00304220(92)90320-P 